\title{
Anaerobiosis and the Activity of Enzymes of Pyrimidine Biosynthesis in Staphylococcus aureus
}

\author{
By M. B. McILLMURRAY* AND JUNE LASCELLES \\ Department of Bacteriology, University of California, \\ Los Angeles, California 90024, U.S.A.
}

\section{(Accepted for publication 20 October 1970)}

\begin{abstract}
SUMMARY
Staphylococcus aureus synthesizes pyrimidines using a pathway similar to that established in Escherichia coli. Soluble and bound forms of dihydroorotate dehydrogenase are present. Both forms are active in 2,6-dichlorophenolindophenol reduction assays; that the particulate enzyme normally links to oxygen via a cytochrome system was shown in studies of a haemrequiring mutant.

Activities of the enzymes of pyrimidine synthesis are six- to 20-fold greater in anaerobically or semi-anaerobically grown bacteria than in those grown in air, unless uracil is present. Aerobic cultures rapidly accumulate dihydroorotate in the medium after transfer to anaerobic conditions; derepression of the dehydrogenase also ensues.

These findings show that the requirement for uracil displayed by Staphylococcus aureus when growing anaerobically is due to its inability to dehydrogenate dihydroorotate in the absence of oxygen: they cannot explain the ability of Escherichia coli to grow anaerobically without uracil.
\end{abstract}

\section{INTRODUCTION}

Staphylococcus aureus grows aerobically in media containing glucose, amino acids and certain vitamins, but under anaerobic conditions supplementation with uracil and pyruvate is required (Richardson, 1936). Acetate replaces pyruvate for anaerobic growth (Gardner \& Lascelles, 1962). The anaerobic requirement for pyruvate or acetate may be attributable to the highly active NAD-linked lactate dehydrogenase which channels the pyruvate formed by glycolysis almost quantitatively to lactate, thereby depriving the bacteria of a source of acetyl units (Garrard \& Lascelles, I968).

In the present work the anaerobic requirement for uracil has been examined by studying enzymes concerned in pyrimidine biosynthesis in staphylococci grown under various conditions. The pathway, established in Escherichia coli and other organisms, is outlined in scheme I. We have given particular attention to dihydroorotate dehydrogenase, since it catalyses the only oxidative step in the pathway and is therefore the most likely to be influenced by anaerobiosis.

\section{METHODS}

Organisms. Staphylococcus aureus 6515, the wild-type strain, was isolated from clinical material; it was maintained on Brucella agar (Difco) slopes. The mutant strain of S. aureus, SG 5 I I VAR, cannot form haems and was originally described by Jensen

* Present address: Wellcome Research Laboratories, Langley Court, Beckenham, Kent. 
\& Thofern (1953); it was maintained on chocolate blood agar slopes. Wild-type Escherichia coli strain w was kept on nutrient agar slopes. The mutant strain E. coli $\mathrm{H} 7$, originally described by Beljanski \& Beljanski (1957), cannot make haems and was therefore kept on chocolate blood agar slopes. All stock cultures were subcultured monthly with $18 \mathrm{~h}$. incubation at $37^{\circ}$ and were stored at $4^{\circ}$.

\section{Scheme I. Outline of pyrimidine biosynthetic pathway}

\begin{tabular}{|c|c|c|c|}
\hline \multirow{2}{*}{$\begin{array}{l}\text { Aspartate } \\
+ \\
\text { carbamoylphosphate }\end{array}$} & Aspartate carbamoyl transferase & \multirow{2}{*}{ Carbamoylaspartate } & Dihydroorotase \\
\hline & $\left(\mathrm{EC}_{2}, 1 \cdot 3.2\right)$ & & $\left(\mathrm{EC}_{3 \cdot 5 \cdot 2 \cdot 3)}\right.$ \\
\hline
\end{tabular}

Dihydroorotate

Dihydroorotate dehydrogenase

(EC I.3.3.I)

Orotidine- $5^{\prime}-$ phosphate
Orotidine-5'-phosphate decarboxylase

(EC 4.I.I.23)
Orotate

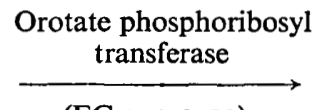

(EC 2.4.2.10)

Uridine- $5^{\prime}$-phosphate

Growth conditions. The basal medium contained Difco Casamino acids and vitamins (Gardner \& Lascelles, 1962), supplemented with 50 mM-glucose and Io mMsodium pyruvate. Aerobic rates of growth were determined in $50 \mathrm{ml}$. cultures in $300 \mathrm{ml}$. nephelometer flasks shaken at $150 \mathrm{rev} / \mathrm{min}$. Anaerobic growth rates were followed with $200 \mathrm{ml}$. cultures in stoppered nephelometer flasks, flushed with nitrogen after inoculation. Growth was measured with a Klett-Summerson photoelectric colorimeter with a no. 42 blue filter; Ioo Klett units corresponded to $0.16 \mathrm{mg}$. dry wt of organisms $/ \mathrm{ml}$. of culture and a standard curve was used to correct for non-linearity at higher densities.

For enzyme studies, bacteria were grown at $37^{\circ}$ from an inoculum of about $10^{6}$ organisms $/ \mathrm{ml}$. under conditions designated as aerobic, semi-anaerobic and anaerobic. Aerobic cultures (I 1.) were grown in 2.5 l. low form flasks incubated on a reciprocal shaker at 76 strokes/min. Semi-anaerobic cultures were incubated statically in 21 . Erlenmeyer flasks filled to the neck and plugged with cotton wool. Anaerobic cultures were contained in 41 . bottles closed with a rubber bung; before inoculation the freshly autoclaved medium was sparged for $30 \mathrm{~min}$. with nitrogen freed of oxygen by bubbling through 0.1 M-vanadium sulphate in N-sulphuric acid over a bed of zinc amalgam (Meites \& Meites, 1948).

Preparation of cell-free extracts. Cultures were harvested in the mid to late log phase of growth and the organisms were washed in one-half the original culture volume of $50 \mathrm{mM}$-tris buffer $(\mathrm{pH} \mathrm{7.5)}$. The washed organisms were suspended in $50 \mathrm{~mm}$-tris buffer (pH 8.4) to I00 mg. dry wt $/ \mathrm{ml}$. and were disrupted by passing twice through a French pressure cell (American Instrument Co., Silver Springs, Maryland) at 18,000 p.s.i. Unbroken cells and large debris were removed by centrifuging the homogenate at I0,000 $\mathrm{g}$ for $10 \mathrm{~min}$. at $4^{\circ}$. When necessary, the crude extracts so obtained were fractionated by centrifugation at $100,000 \mathrm{~g}$ for $\mathrm{I} \mathrm{h}$. at $4^{\circ}$; after removal of the supernatant the pellet was suspended to the original volume in 0.1 M-tris buffer $(\mathrm{pH} \mathrm{8.4)}$ Analytical methods. Dihydroorotate was determined by the method of Yates \& Pardee (1956). Protein was determined by the method of Lowry, Rosebrough, Farr \& Randall (I95I) using bovine serum albumin as standard. 
Assay of enzyme activities. Aspartate carbamoyl transferase was assayed by determination of the inorganic phosphate released during the reaction (Shepherdson \& Pardee, 1960). Dihydroorotate dehydrogenase was determined using as the hydrogen acceptor either oxygen or an artificial dye system. With oxygen, formation of orotate was followed spectrophotometrically at $290 \mathrm{~nm}$. in open cuvettes (Beckwith, Pardee, Austrian \& Jacob, 1962). In the assay with artificial acceptors, the rate of reduction of 2,6-dichlorophenolindophenol was followed using phenazine methosulphate as intermediate hydrogen carrier. Reaction mixtures contained in a final volume of I ml.: tris buffer ( $\mathrm{pH} \mathrm{8.4),} \mathrm{I00} \mu$ moles; 2,6-dichlorophenolindophenol, sodium salt, $0 . \mathrm{I} \mu$ mole; phenazine methosulphate, $0.32 \mu$ mole; $\mathrm{KCN}$ (adjusted to $\mathrm{pH} 8$ with $\mathrm{N}-\mathrm{HCl}$ ), $2 \mu$ moles; extract, $0.0 \mathrm{I}$ to $0.2 \mathrm{mg}$. protein. The reaction was started by addition of $\mathrm{L}$-dihydroorotic acid (I $\mu$ mole) to one cuvette and the decrease in extinction at $600 \mathrm{~nm}$. was measured against a 'blank' cuvette from which substrate was omitted. The activity of the dehydrogenase was calculated from the initial rate assuming a millimolar extinction coefficient for dichlorophenolindophenol at $600 \mathrm{~nm}$. of $2 \mathrm{I}$. The joint activities of orotate phosphoribosyl transferase and orotidine- 5 -phosphate decarboxylase were assayed spectrophotometrically by following the disappearance of orotic acid in the presence of 5-phosphoribosyl-I-pyrophosphate (Beckwith et al. I962).

Spectrophotometric assays were performed using a Cary spectrophotometer, model I4, equipped with a 0 to $0 . \mathrm{I}$ absorbance slide wire. All assays were conducted at room temperature (about $25^{\circ}$ ).

Special chemicals. All special chemicals were from Sigma Chemical Co. (St Louis, Missouri) with the exception of carbamoyl phosphate, which was from Calbiochem (Los Angeles, California). Stock solutions of haemin were prepared as described by Lascelles, Rittenberg \& Clark-Walker (1969).

\section{RESULTS}

Anaerobic and aerobic growth rates of Staphylococcus aureus. Under anaerobic conditions $S$. aureus 6515 grew slowly in the unsupplemented basal medium but the growth rate was considerably improved by addition of uracil (Fig. I). Little or no growth occurred anaerobically in the absence of added pyruvate, irrespective of the presence of uracil. Maximum rates of growth were observed under aerobic conditions in the basal medium (Fig. 1). The aerobic growth rate was not affected by addition of uracil nor by omission of pyruvate.

Similar growth patterns were obtained with 50 other isolates of Staphylococcus aureus and seven strains of $S$. epidermidis.

Pathway of pyrimidine synthesis in Staphylococcus aureus. The biosynthesis of pyrimidines in $S$. aureus 6515 was shown by isotopic techniques and by the demonstration of key enzymic activities, to be similar to that established in Escherichia coli and other organisms (Roberts et al. 1955; Yates \& Pardee, 1956).

[U-14]C-L-Aspartate was incorporated by growing cultures into nucleic acids and chromatographic fractionation (Smith \& Markham, I950) showed that $99 \%$ of the label in the nucleic acid fraction was located in the pyrimidines. Uracil reduced incorporation of the isotope by $90 \%$. Enzymes of the biosynthetic pathway were present in extracts of organisms grown aerobically and anaerobically (Table I). 
Dihydroorotate dehydrogenase in Staphylococcus aureus. The dehydrogenase was initially studied in extracts of aerobically grown staphylococci, using both the oxygen linked assay and the assay with artificial electron acceptors. The latter method showed that the particulate fraction of cell-free extracts had the highest specific activity, but over $70 \%$ of the total activity was located in the soluble fraction (Table 2). This activity was not sedimented by centrifuging for $16 \mathrm{~h}$. at $100,000 \mathrm{~g}$. With oxygen as the

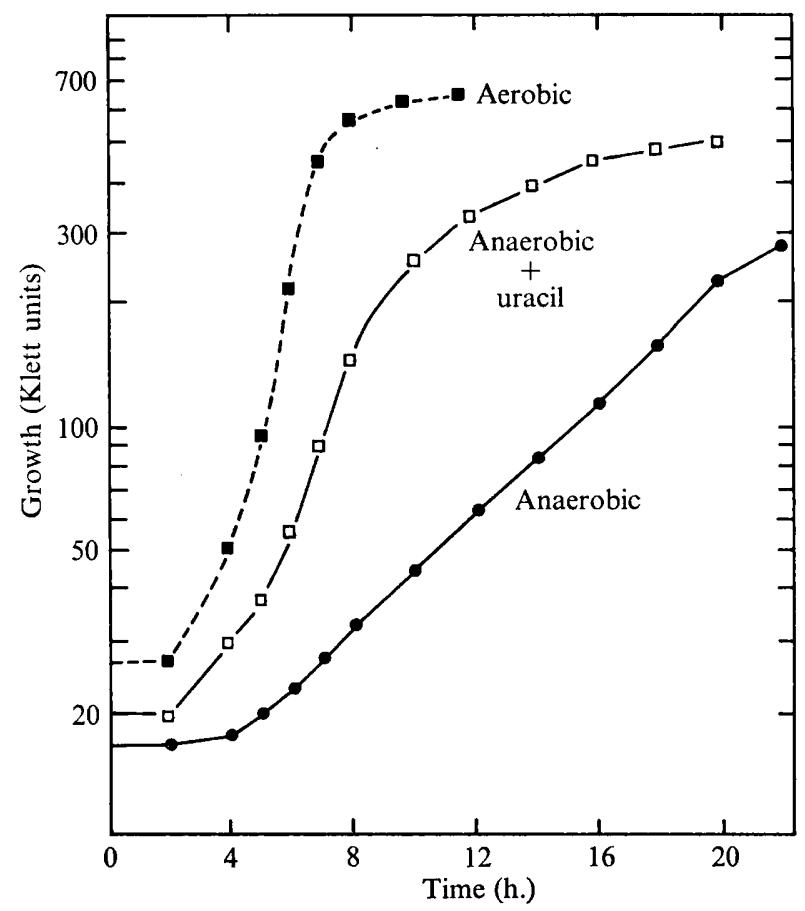

Fig. 1. Growth of Staphylococcus aureus 6515. Cultures were grown aerobically in the basal medium $(\square--\square)$ or anaerobically without $(-)$ ) and with $0 \cdot$ I mM-uracil $(\square-\square)$.

Table I. Activity of pyrimidine biosynthetic enzymes in extracts of Staphylococcus aureus 6515

Organisms were grown aerobically or anaerobically in the basal medium with $0 \cdot 1$ mM-uracil added as shown. Enzyme activities were assayed in cell-free extracts as described in the Methods section. Dihydroorotate dehydrogenase was assayed by the dye reduction method.

\begin{tabular}{|c|c|c|}
\hline \multicolumn{3}{|c|}{$\begin{array}{c}\text { Enzyme activity } \\
\text { (nmoles substrate or product/min./mg. protein) }\end{array}$} \\
\hline $\begin{array}{l}\text { Aspartate } \\
\text { carbamoyl } \\
\text { transferase }\end{array}$ & $\begin{array}{l}\text { Dihydroorotate } \\
\text { dehydrogenase }\end{array}$ & $\begin{array}{l}\text { Orotate phos- } \\
\text { phoribosyl } \\
\text { transferase and } \\
\text { orotidine- }-5^{\prime}- \\
\text { phosphate } \\
\text { decarboxylase }\end{array}$ \\
\hline
\end{tabular}

Aerobic: basal medium

Anaerobic: basal medium

Anaerobic: basal medium supple-

100
1436

1436
200

20
315
12

I I

65 mented with $0 \cdot 1 \mathrm{~mm}$-uracil 
acceptor, activity was confined to the particulate fraction, suggesting the participation of a membrane-bound respiratory chain. This was supported by the observation that Io mM-potassium cyanide inhibited the aerobic activity by $90 \%$, but did not affect the activity with artificial acceptors.

\section{Table 2. Distribution of dihydroorotate dehydrogenase activity in extracts of Staphylococcus aureus 6515}

Organisms were grown aerobically in basal medium and the crude extract was fractionated by centrifuging for $\mathrm{I} \mathrm{h}$. at $100,000 \mathrm{~g}$. The pellet was resuspended to the original volume in $0 . \mathrm{I}$ M-tris buffer ( $\mathrm{pH} \mathrm{8.4).} \mathrm{Enzyme} \mathrm{activities} \mathrm{were} \mathrm{determined} \mathrm{in} \mathrm{the} \mathrm{soluble} \mathrm{and} \mathrm{particulate}$ fractions as described in the Methods.

$\begin{array}{lcccc}\text { Fraction } & \overbrace{\begin{array}{c}\text { Specific activity } \\ \text { (nmoles/min./mg. } \\ \text { protein) }\end{array}}^{\text {Dotal }} & \overbrace{\begin{array}{c}\text { Specific activity } \\ \text { (nmoles/min./mg. } \\ \text { protein) }\end{array}}^{\text {Octivity (\%) }} & \begin{array}{c}\text { Total } \\ \text { activity (\%) }\end{array} \\ \text { Crude extract } & 47 & 100 & 12 & \text { Ioo } \\ \text { Supernatant } & 35 & 72 & 1 & 6 \\ \text { Particles } & 65 & 28 & 74 & 94\end{array}$

Table 3. Dihydroorotate dehydrogenase activity in particles of haem-deficient mutants of Staphylococcus aureus and Escherichia coli

\begin{tabular}{|c|c|c|c|c|}
\hline \multicolumn{5}{|c|}{$\begin{array}{l}\text { Staphylococcus aureus SG } 5 \text { I I VAR and } \\
\text { medium supplemented with haemin a } \\
\text { for I h. at I00,000g. The pellets we } \\
\text { buffer }(\mathrm{pH} 8 \cdot 4) \text { and assayed by the dye } \\
\text { without and with I } \mu_{\mathrm{M} \text {-haemin. }}\end{array}$} \\
\hline & \multirow[b]{3}{*}{$\begin{array}{l}\text { Haemin in } \\
\text { growth } \\
\text { medium }\end{array}$} & \multicolumn{3}{|c|}{$\begin{array}{l}\text { Dihydroorotate dehydrogenase activity } \\
\text { (nmoles/min./mg. protein) }\end{array}$} \\
\hline & & \multirow[b]{2}{*}{$\begin{array}{l}\text { Dye } \\
\text { reduction } \\
\text { assay }\end{array}$} & \multicolumn{2}{|c|}{ Oxygen-linked assay } \\
\hline Organism & & & $\begin{array}{l}\text { Without } \\
\text { haemin }\end{array}$ & $\begin{array}{l}\text { With I } \mu \mathrm{M}- \\
\text { haemin }\end{array}$ \\
\hline S. aureus SG 5 I I VAR & $\begin{array}{c}0 \\
2 \mu_{\mathrm{M}}\end{array}$ & $\begin{array}{r}194 \\
79\end{array}$ & $\begin{array}{r}2 \\
63\end{array}$ & $\begin{array}{c}94 \\
\text { Not } \\
\text { determined }\end{array}$ \\
\hline E. coli $\mathrm{H} 7$ & $\begin{array}{c}0 \\
2 \mu \mathrm{M}\end{array}$ & $\begin{array}{l}68 \\
55\end{array}$ & $\begin{array}{r}0 \\
6 \mathrm{I}\end{array}$ & $\begin{array}{c}27 \\
\text { Not } \\
\text { determined }\end{array}$ \\
\hline
\end{tabular}

The involvement of a cytochrome system in the oxygen-linked assay was examined in the particulate fraction of extracts of the mutant strain of Staphylococcus aureus SG 5I I VAR which does not make haems. This organism grows in aerated cultures at a maximum rate in the absence of haemin provided that the medium contains uracil and pyruvate; these supplements are not required when haemin is supplied. (Gardner \& Lascelles, 1962). Dehydrogenase activity with oxygen as the acceptor was found in preparations from organisms grown with haemin (Table 3). In contrast, such activity was negligible in particles from the mutant grown without haemin though there was abundant dye-linked activity (Table 3). Addition of haemin to the aerobic assay mixture from the mutant restored the activity to that found in particles from bacteria grown with haemin (Table 3); this activity was inhibited by ro mM-cyanide. 
Effect of growth conditions on enzyme activities in Staphylococcus aureus. The growth rate of $S$. aureus 6515 under anaerobic or semi-anaerobic conditions was retarded unless the medium was supplemented with uracil (Fig. I, 2). Yet, assay of the biosynthetic enzymes showed that organisms grown under such conditions had 6 to 20 times the activities found in organisms grown with high aeration (Table I). Addition of uracil to the medium abolished the increase in activity (Table 1).

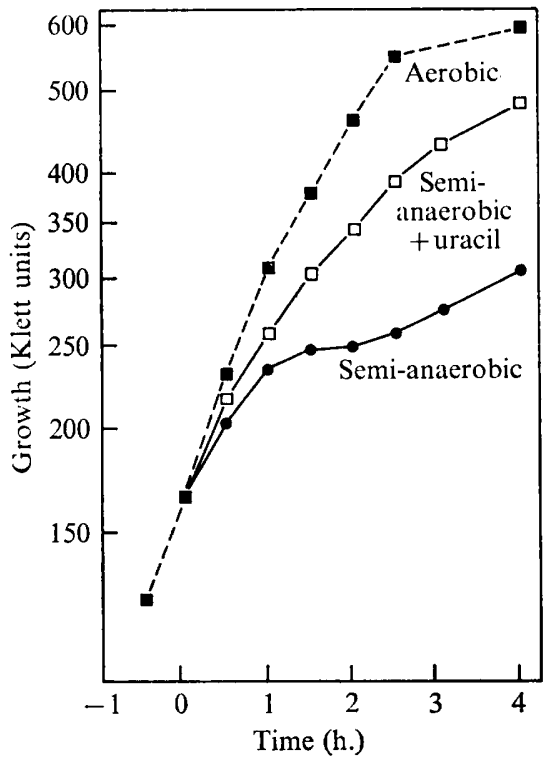

Fig. 2

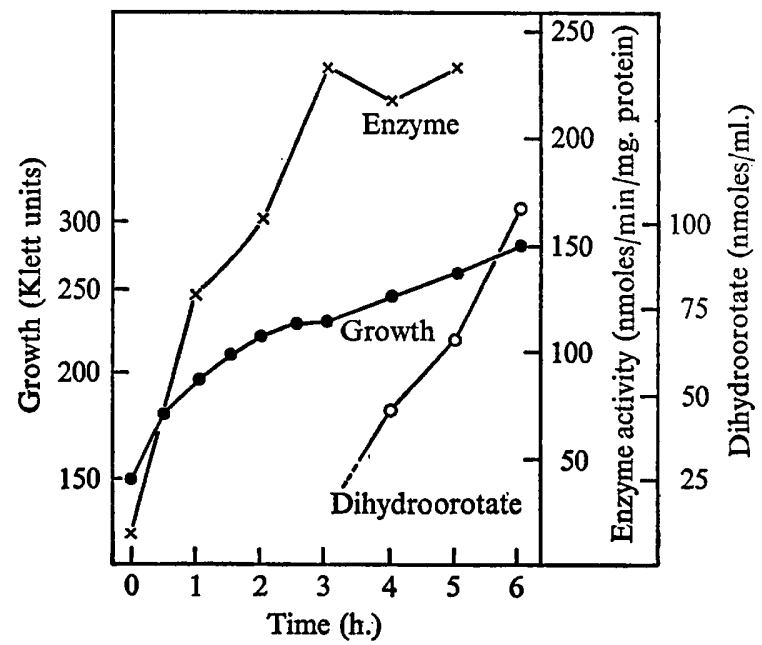

Fig. 3

Fig. 2. Effect of semi-anaerobic conditions on growth of Staphylococcusaureus 6515 . Cultures growing aerobically in the basal medium with or without uracil were transferred at zero time to semi-anaerobic conditions. - - $\mathbf{n}$, Aerobic conditions throughout in basal medium alone; $\square-\square$, semi-anaerobic conditions in basal medium with $0.1 \mathrm{~mm}$-uracil; semi-anaerobic conditions in basal medium alone.

Fig. 3. Dihydroorotate dehydrogenase and accumulation of dihydroorotate in cultures of Staphylococcus aureus 6515 after transfer from aerobic to semi-anaerobic conditions. Cultures growing aerobically in the basal medium were transferred at zero time to semianaerobic conditions. Dihydroorotate was estimated in samples of the culture fluid after removal of the cells and dehydrogenase activity was measured by the dye reduction assay in cell-free extracts. $\times$, Dihydroorotate dehydrogenase activity (nmoles dihydroorotate/ min./mg. protein); 9 , growth (Klett units); O, dihydroorotate (nmoles/ml. culture).

The elevated activities could arise from derepression of enzyme formation in response to pyrimidine starvation; this could be a consequence of the organism's inability to dehydrogenate dihydroorotate when oxygen is lacking. Observations with cultures transferred from high aeration to semi-anaerobic conditions supported this notion. The growth curve of unsupplemented cultures showed a plateau soon after the transfer and then growth was resumed at a slow rate (Fig. 2). Cultures containing uracil did not show the plateau and continued to grow after the transfer at a slightly slower rate than the control incubated throughout with high aeration (Fig. 2). Addition of uracil during the postshift lag period restored the growth rate to that found with cultures supplied throughout with uracil. 
Assay of dihyroorotate dehydrogenase in extracts of bacteria from unsupplemented cultures at periods after the transition to semi-anaerobic conditions showed a rapid increase in specific activity to a level about 20 times that found initially (Fig. 3). This increase in activity was not found in cultures supplemented with uracil.

Culture supernatants were also analysed for dihydroorotate. This compound accumulated after the shift to semi-anaerobic conditions (Fig. 3), but was not detected in cultures growing aerobically or in those supplemented with uracil.

Observations with Escherichia coli. A dihydroorotate dehydrogenase-ubiquinone reductase complex has been isolated from particles of $E$. coli; oxidation of dihydroorotate in vivo is presumed to proceed by interaction of this complex with the cytochromes of the respiratory chain (Kerr \& Miller, 1968). It might be expected that anaerobic growth of E. coli, like that of Staphylococcus aureus, would be limited by pyrimidine synthesis, unless alternative mechanisms are available for disposal of reducing equivalents derived from the oxidation of dihydroorotate. Growth and dehydrogenase activity were examined in $E$. coli grown in the same media and under similar conditions to those used with $S$. aureus. Unlike the latter, the anaerobic growth of wild-type $E$. coli was not affected by added uracil, nor did dihydroorotate accumulate when aerobic cultures were transferred to anaerobic or semi-anaerobic conditions. The activity of dihydro-orotate dehydrogenase was similar in extracts of $E$. coli grown either with or without oxygen and was not greatly diminished by growth with added uracil. Mutant $\mathrm{H} 7$ fails to make haems and is similar to $S$. aureus SG 5I I VAR in that it makes functional cytochromes only when grown with haemin. Particles from H 7 behaved like those from the staphylococcal mutant (Table 3). Dihydroorotate dehydrogenase linked to oxygen was observed only in particles from cells grown with haemin. Oxygen-linked activity was restored to preparations from haem-depleted cells by addition of haemin in vitro. Unlike the staphylococcal mutant, enzyme activity measured by dye reduction did not differ significantly in preparations from cells grown with or without haemin (Table 3).

\section{DISCUSSION}

The anaerobic requirement of Staphylococcus aureus for uracil can be attributed to failure at the stage of dihydroorotate dehydrogenation in the absence of a functional respiratory chain. The accumulation of dihydroorotate in cultures after transfer to semi-anaerobic conditions provides in vivo evidence that this dehydrogenation is the critical step. In vitro, the participation of cytochromes in the oxygen-linked activity is shown by the inhibition caused by cyanide and by the behaviour of the mutant strain SG 5II VAR. This mutant apparently makes apo-cytochromes when grown without haemin, since addition of haemin to deficient particles restores nitrate reductase activity and re-establishes a cytochrome absorption spectrum (Chang \& Lascelles, 1963). Similar particles from the mutant exhibited oxygen-linked dihydroorotate dehydrogenase activity only upon addition of haemin.

The particulate dehydrogenase of Staphylococcus aureus behaves like that from Escherichia coli with respect to its linkage with oxygen. The dihydroorotate dehydrogenase-ubiquinone reductase complex which has been isolated from particles of $E$. coli contains FMN, non-haem iron and ubiquinone and is thought to interact in vivo with cytochromes of the electron transport chain (Kerr \& Miller, 1968). The present observation with haemin-deficient particles from $E$. coli $\mathrm{H}_{7}$ supports this view. 
However, $E$. coli does not require uracil for anaerobic growth and it must therefore possess some alternative mechanism for disposal of reducing equivalents derived from dihydroorotate. This also applies to other organisms which are capable of growing anaerobically in the absence of added pyrimidines and raises the question of the nature of the electron acceptors linked to dihydroorotate dehydrogenase. The $E_{0}^{\prime}$ of the orotatedihydroorotate couple $(-0.252 \mathrm{~V})$ is not favourable for reaction of dihydroorotate with pyridine nucleotides (Kerr \& Miller, 1968). This difficulty could possibly be overcome by the intervention of ATP-dependent reactions; alternatively, an anaerobic electron acceptor of higher $E_{0}^{\prime}$ might be utilized, e.g. the fumarate-succinate couple.

The significance of the large amount of soluble dehydrogenase found in Staphylococcus aureus is not clear. In other organisms, including Escherichia coli, the biosynthetic enzyme is entirely membrane-bound (Taylor, Taylor \& Eames, 1966). Soluble forms of dihydroorotate dehydrogenase are found in high concentration in organisms which use orotate as energy source (Aleman \& Handler, 1967; Kerr \& Miller, 1967).

The increased activity of enzymes of pyrimidine biosynthesis observed in Staphylococcus aureus grown under conditions of oxygen limitation is presumed to represent derepression, since supplementation of the medium with uracil abolished the increase. Enzyme formation may be influenced by the intracellular concentration of a 'corepressor' molecule, possibly a pyrimidine nucleotide. Failure to dehydrogenate dihydroorotate when oxygen is lacking would reduce the concentration of corepressor below the critical level with consequent derepression of the enzymes. The kinetics of development of enzyme activity after transfer of aerobic cultures to semi-anaerobic conditions are consistent with this interpretation (Fig. 3). Further support is provided by the haem-deficient mutant SG 5 I I VAR. Pyrimidine starvation occurs in this organism when it is grown aerobically without haemin (Gardner \& Lascelles, I962). The dihydroorotate dehydrogenase activity of such cells was considerably higher than that found in organisms grown with haemin (Table 3). In Escherichia coli derepression of the enzymes of pyrimidine biosynthesis has been observed with auxotrophic mutants grown under conditions of pyrimidine starvation (Beckwith et al. 1962; Dennis \& Herman, 1970). Our observations with $E$. coli show that anaerobic dehydrogenation of dihydroorotate does not become a critical step in provoking derepression of the biosynthetic enzymes. Enzyme levels were similar in cells grown aerobically or anaerobically and dihydroorotate did not accumulate in cultures after transfer from aerobic to semi-anaerobic or anaerobic conditions.

This work was supported by grants from the National Institutes of Health (AM-II 148) and the National Science Foundation (GB-7575). M.B. M. held a predoctoral fellowship from the National Institutes of Health (GM-34, 274) at the time of this work.

\section{REFERENCES}

Aleman, V. \& Handler, P. (1967). Dihydroorotate dehydrogenase. I. General properties. Journal of Biological Chemistry 242, 4087-4096.

Beckwith, J. R., Pardee, A. B., Austrian, R. \& JaCob, F. (1962). Co-ordination of the synthesis of the enzymes in the pyrimidine pathway of E. coli. Journal of Molecular Biology 5, 618-634.

BeljansKi, M. \& Beljanski, M. (1957). Sur la formation d'enzymes respiratoires chez un mutant d'Escherichia coli streptomycin-résistant et auxotrophe pour l'hémine. Annales de l'Institut Pasteur, Paris 92, 396-412. 
Chang, J. P. \& LASCELles, J. (1963). Nitrate reductase in cell-free extracts of a haemin-requiring strain of Staphylococcus aureus. Biochemical Journal 89, 503-510.

Dennis, P. P. \& Herman, R. K. (1970). Pyrimidine pools and macromolecular composition of pyrimidine-limited Escherichia coli. Journal of Bacteriology I02, I $18-123$.

GARDNER, J. F. \& LASCELLES, J. (I962). The requirement for acetate of a streptomycin-resistant strain of Staphylococcus aureus. Journal of General Microbiology 29, 157-164.

GaRRARD, W. T. \& LASCELles, J. (1968). Regulation of Staphylococcus aureus lactate dehydrogenase. Journal of Bacteriology 95, 152-156.

JENSEN, J. \& THOFERN, E. (I953). Chlorhämin (Ferriporphyrinchlorid) als Bakterienwuchsstoff I. Zeitschrift für Naturforschung 8b, 599-603.

KeRR, C. T. \& MiLleR, R. W. (1967). Soluble NADP-linked dihydroorotate dehydrogenase from a pseudomonad. Canadian Journal of Biochemistry 45, I295-I307.

KeRR, C. T. \& MilLER, R. W. (I968). Dihydroorotate-ubiquinone reductase complex of Escherichia coli B. Journal of Biological Chemistry 243, 2963-2968.

Lascelles, J., Rittenberg, B. \& Clark-Walker, G. D. (I969). Growth and cytochrome synthesis in a haemin-requiring mutant of Spirillum itersonii. Journal of Bacteriology 97, 455-456.

Lowry, O. H., Rosebrough, N. J., Farr, A. L. \& Randall, R. J. (195I). Protein measurements with the Folin phenol reagent. Journal of Biological Chemistry 193, 265-275.

Meites, L. \& Mertes, T. (1948). Removal of oxygen from gas streams. Analytical Chemistry 20, 984-985.

RichaRdSON, G. M. (1936). The nutrition of Staphylococcus aureus. Necessity for uracil in anaerobic growth. Biochemical Journal 30, 2184-2190.

Roberts, R. B., Abelson, P. H., Cowie, D. B., Bolton, E. T. \& Britten, R. (1955). Studies of Biosynthesis in Escherichia coli. Carnegie Institute of Washington, Publication 607.

Shepherdson, M. \& Pardee, A. B. (1960). Production and crystallization of aspartate transcarbamylase. Journal of Biological Chemistry 235, 3233-3237.

Smith, J. D. \& MARKhaM, R. (1950). Chromatographic studies on nucleic acids. II. The quantitative analysis of ribonucleic acids. Biochemical Journal 46, 509-513.

TAYLOR, W. H., TAYloR, M. L. \& Eames, D. F. (I966). Two functionally different dihydroorotic dehydrogenases in bacteria. Journal of Bacteriology 9x, 225I-2256.

YAtes, R. A. \& PARDEe, A. B. (1956). Pyrimidine biosynthesis in Escherichia coli. Journal of Biological Chemistry 221, 743-756. 